\title{
The Associated Risk Factors for Entrapment Neuropathy in the Upper Extremity: The Locomotive Syndrome and Health Outcome in Aizu Cohort Study (LOHAS)
}

\author{
Kenichi Otoshi ${ }^{*}$, Shinichi Kikuchi ${ }^{2}$, Nobuyuki Sasaki², Miho Sekiguchi², Koji Otani², \\ Tsukasa Kamitani ${ }^{3}$, Shingo Fukuma3 ${ }^{3}$, Shunichi Fukuhara ${ }^{3}$, Shinichi Konno ${ }^{2}$ \\ ${ }^{1}$ Department of Sports Medicine, School of Medicine, Fukushima Medical University, Fukushima, Japan \\ ${ }^{2}$ Department of Orthopaedic Surgery, School of Medicine, Fukushima Medical University, Fukushima, Japan \\ ${ }^{3}$ Department of Healthcare Epidemiology, Graduate School of Medicine and Faculty of Medicine, Kyoto University, Kyoto, Japan \\ Email: *kenichiotoshi@email.plala.or.jp
}

How to cite this paper: Otoshi, K., Kikuchi, S., Sasaki, N., Sekiguchi, M., Otani, K., Kamitani, T., Fukuma, S., Fukuhara, S. and Konno, S. (2018) The Associated Risk Factors for Entrapment Neuropathy in the Upper Extremity: The Locomotive Syndrome and Health Outcome in Aizu Cohort Study (LOHAS). Health, 10, 823-837. https://doi.org/10.4236/health.2018.106062

Received: May 24, 2018

Accepted: June 25, 2018

Published: June 28, 2018

Copyright (ㅇ 2018 by authors and Scientific Research Publishing Inc. This work is licensed under the Creative Commons Attribution International License (CC BY 4.0).

http://creativecommons.org/licenses/by/4.0/

\begin{abstract}
Purpose: Although carpal tunnel syndrome (CTS) and cubital tunnel syndrome (CuTS) are the most common neuropathies in the upper extremities, there have been few studies describing the etiology and associated factors in the general population. The purpose of this study was to investigate and clarify the etiology and associated factors for CTS and CuTS in the Japanese general population. Methods: A total of 1875 participants, who participated in health checkups conducted in rural areas in Japan in 2010, were enrolled. The prevalence of CTS and CuTS was investigated. Logistic regression models were performed to examine the relationship between CTS and CuTS and correlated factors such as occupational status, smoking and alcohol preferences, and medical characteristics. Results: The overall prevalence of CTS and CuTS was $2.0 \%$ and $2.2 \%$, respectively. With regards to CTS, female subjects showed 7.33-times higher risk of CTS compared with male subjects. In addition, hypertension was also at high risk of CTS (5.56-times higher in borderline and 4.55-times higher in definite hypertension compared with normal blood pressure). However, there were no significant associations between $\mathrm{CuTS}$ and age, gender, occupation, smoking and alcohol preferences, or metabolic factors. Conclusions: CTS was associated with female gender and hypertension, whereas there was no obvious risk factor contributing to the onset of CuTS.
\end{abstract}

\section{Keywords}

Risk Factor, Carpal Tunnel Syndrome, Cubital Tunnel Syndrome, Metabolic Factor, Prevalence 


\section{Introduction}

It has been reported that peripheral nerve entrapment syndromes involve chronic irritation and compression where the nerves pass through anatomical stenotic lesions and fibro-osseous canals. In the upper extremities, various peripheral nerve neuropathies have been reported, and carpal tunnel syndrome (CTS) and cubital tunnel syndrome (CuTS) have been reported as the most common peripheral nerve disorders [1] [2].

There have been several reports describing the etiology of CTS and CuTS. The results of almost all those studies suggest that CTS occurs more commonly in women, with an annual incidence of 1.5 per 1000 compared to 0.5 per 1000 for men [3]. Recently, a CTS prevalence of $2.3 \%$ to $4.3 \%$ has been reported in two large cohorts of French workers [4].

On the other hand, male gender predisposes to CuTS with an incidence of 24.7 per 100,000 people per year in the general population [5], and, depending on the case definition, prevalence rates in the general population have been estimated at between $7 \%-19 \%[6]$.

Several studies have demonstrated the associated risk factors of CTS and CuTS. Diabetes, thyroid dysfunction, fluid retention from pregnancy or menopause, high blood pressure, autoimmune disorders such as rheumatoid arthritis, and fractures or trauma to the wrist have also been considered as risk factors of CTS [7] [8] [9] [10] [11].

As with CuTS, fractures around the elbow joint [12] [13] [14], smoking [15], holding a tool in the same position [16], and education [12] have been found to be risk factors.

However, since most of the reported risk factors were investigated using a hospital-based case control study or epidemiologic study of the working population, little is currently known about the relative contributions of associated factors to CTS and CuTS in the general population, and a large population-based research is needed to clarify the associated factors influencing the onset of these neuropathies.

The aim of the current study, a large epidemiologic study, was to clarify the prevalence of CTS and CuTS in the Japanese general population and investigate the associated risk factors using cross-sectional data from the Locomotive Syndrome and Health Outcome in Aizu Cohort Study (LOHAS) [17].

\section{Materials and Methods}

The LOHAS is an ongoing prospective cohort study of locomotive disorders and health outcomes in Japanese subjects aged 40 - 74 years [17]. The subjects were National Health Insurance (NHI) beneficiaries receiving annual health check-ups conducted by local governments in the towns of Minami-Aizu and Tadamiin Fukushima Prefecture, Japan. Inclusion criteria included subjects who had participated in annual health checkups conducted in 2010. Written informed consent was obtained from all subjects, and the institutional ethics 
committee approved the study protocol.

\subsection{Sociodemographic Characteristics}

We collected sociodemographic data including sex, age, occupation, and personal medical, smoking, and alcohol history, as measured via self-completed questionnaire, and body mass index (BMI), as measured by local nurse practitioners or clinicians. Regarding occupation, the subject's current or longest-lasting former occupation was classified four categories as follows: manual, non-manual, service, and other. Manual work included agriculture, transportation, and manufacturing, non-manual work included office work, administration, and professional, and service work included sales and the service industry. The population of unemployed subjects was categorized as having no occupation [17]. As for smoking status, there were three groups: current smoker, former smoker, and never smoker [18]. With regard to alcohol consumption, there were four groups into which the subjects were categorized: every day, sometimes, rarely, and never [18]. We defined as "overweight" when a BMI was $\geq 25 \mathrm{~kg} / \mathrm{m}^{2}$ based on the criteria of the Japan Society for the Study of Obesity [19].

\subsection{Clinical Characteristics}

We also assessed clinical characteristics as systolic blood pressure (SBP), diastolic blood pressure (DBP), glycated hemoglobin (HbA1c), low-density lipoprotein cholesterol (LDL-C), high-density lipoprotein cholesterol (HDL-C), and triglyceride (TG) serum levels. According to the Japanese Society of Hypertension Guidelines for the Management of Hypertension [20], the subjects were categorized into three groups based on their SBP and DBP: normal (SBP $<130 \mathrm{mmHg}$ and DBP $<85 \mathrm{mmHg}$ ), definite (SBP $\geq 140 \mathrm{mmHg}$ or DBP $\geq 90 \mathrm{mmHg}$ ), and borderline. The criteria recommended by the Japan Diabetes Society (2010) are used to define chronic hyperglycemia. Three groups were made based on HbAlc: favorable control (HbAlc < 5.5), suspected (HbAlc, 5.6 - 6.4), and definite $(\mathrm{HbAlc} \geq 6.5)$ [21]. The hyperlipidemic was defined if at least one of the following three criteria was satisfied: fasting serum LDL-C level is $>140 \mathrm{mg} / \mathrm{dL}$, TG level is $>150 \mathrm{mg} / \mathrm{dL}$, or HDL-C level is $<40 \mathrm{mg} / \mathrm{dL}$, which are recommended by the Japan Atherosclerosis Society [22]. The criteria from the Examination Committee of Criteria for Metabolic Syndrome in Japan (2005) The metabolic syndrome was defined if the waist circumference was $\geq 85 \mathrm{~cm}$ for men and $\geq 90$ $\mathrm{cm}$ for women and at least two of the following three criteria were satisfied: TG is $\geq 150 \mathrm{mg} / \mathrm{dL}$, HDL-C level is $\leq 40 \mathrm{mg} / \mathrm{dL}$, or receiving lipid-lowering therapy; have a SBP of $\geq 130 \mathrm{mmHg}$, a DBP of $\geq 85 \mathrm{mmHg}$, or be receiving antihypertensive therapy; and at least one of the following two criteria was satisfied: a fasting plasma glucose level is $\geq 110 \mathrm{mg} / \mathrm{dL}$ or receiving antihyperglycemic therapy [23].

\subsection{Clinical Symptom and Health-Related Quality of Life}

The upper extremity disability was assessed using the Japanese version of the shortened Disabilities of the Arm, Shoulder and Hand (The Quick DASH) [24]. 
The general health-related quality of life (HRQOL) was assessed using the Medical Outcome Study Short Form 12-Item Health Survey (SF-12) [25]. We calculated the scores for a mental component summary (MCS) and physical component summary (PCS).

\subsection{Assessment of CTS and CuTS}

CTS and CuTS diagnoses were based on the symptoms presented and clinical signs observed via a standardized physical examination. The diagnostic criteria of CTS were subjective neurological symptoms around the median nerve area, and either a positive Tinel's sign at the carpal tunnel or a positive carpal tunnel compression test [26] [27]. The CuTS diagnostic criteria were subjective neurological symptoms around the ulnar nerve area, and either a positive Tinel's sign at the cubital tunnel or a positive elbow flexion test [28].

\subsection{Statistical Analysis}

We described the characteristics of all subjects (analyzed and excluded)as appropriate indices by presence of CTS or CuTS. The Chi squared test for categorical variables, and Student's $t$ test for continuous variables were used to compare the each characteristics between the subjects with and without CTS or CuTS. To explore the associated factors for CTS or CuTS, separated logistic regression analysis were performed. All tests of statistical significance were two-tailed, and $P$ values of less than 0.05 were considered statistically significant. All analyses were conducted using JMP version 10.0.2 (SAS Institute Inc, Cary, NC).

\section{Results}

\subsection{Study Subject and Characteristics}

Of the 2505 participants in the LOHAS baseline survey, 80 participants who did not receive special health check exam or physical exam and 550 participants who had at least one missing value were excluded. This left 1875 subjects to be ultimately enrolled in the present study for analysis (Figure 1). The characteristics of the study population are described in Table 1 . The subjects included in this study were more likely to be older, male, smokers, and have a higher prevalence of hypertension history.

\subsection{Prevalence of CTS and CuTS}

The prevalence of CTS and CuTS are described in Table 2. The overall prevalence of CTS and CuTS was $2.0 \%$ and $2.2 \%$, respectively. In addition, the prevalence of CTS was significantly higher in female compared with male subjects (3.0\% in females vs $0.6 \%$ in males), whereas no significant difference was observed between the male and female subjects regarding CuTS. In both CTS and CuTS, there were no significant differences among the age groups in both the male and female subjects. 


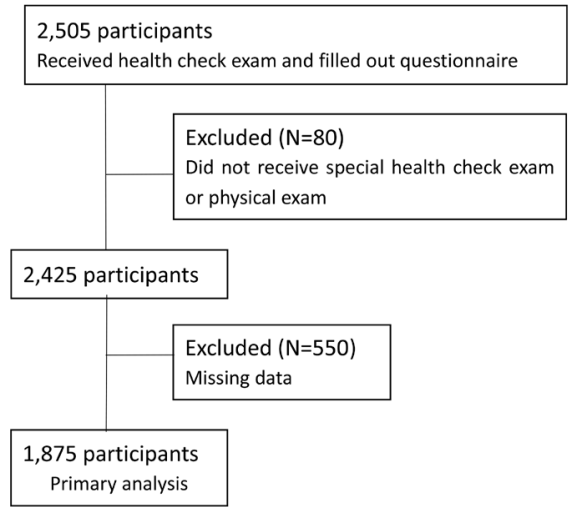

Figure 1. Study flow chart.

Table 1. Baseline characteristics of analyzed population.

\begin{tabular}{|c|c|c|c|c|c|}
\hline & & $\begin{array}{l}\text { All subjects } \\
(\mathrm{N}=2425)\end{array}$ & $\begin{array}{l}\text { Excluded subjects } \\
\qquad(\mathrm{N}=550)\end{array}$ & $\begin{array}{l}\text { Analyzed subjects } \\
\qquad(\mathrm{N}=1875)\end{array}$ & $\mathrm{P}$-value \\
\hline \multicolumn{6}{|l|}{ Age } \\
\hline$\leq 59$ & & $368(15.2 \%)$ & $100(18.5 \%)$ & $268(14.3 \%)$ & \multirow{3}{*}{0.029} \\
\hline $60-69$ & & $843(34.9 \%)$ & $170(31.4 \%)$ & $673(35.9 \%)$ & \\
\hline$\geq 70$ & & $1205(49.9 \%)$ & $271(50.1 \%)$ & $934(49.8 \%)$ & \\
\hline \multicolumn{6}{|l|}{ Gender } \\
\hline Male & & $983(40.7 \%)$ & $161(29.8 \%)$ & $822(43.8 \%)$ & \multirow{2}{*}{$<0.001$} \\
\hline Female & & $1433(59.3 \%)$ & $380(70.2 \%)$ & $1053(56.2 \%)$ & \\
\hline \multicolumn{6}{|l|}{ Smoking history } \\
\hline No & & $1571(65.1 \%)$ & $403(75.1 \%)$ & $1168(62.3 \%)$ & \multirow{2}{*}{$<0.001$} \\
\hline Yes & & $841(34.9 \%)$ & $134(24.9 \%)$ & $707(37.7 \%)$ & \\
\hline \multicolumn{6}{|l|}{ Alcohol consumption } \\
\hline Never & & $768(32.1 \%)$ & $171(33.0 \%)$ & $597(31.8 \%)$ & \multirow{2}{*}{0.632} \\
\hline Current & & $1626(67.9 \%)$ & $348(67.0 \%)$ & $1278(68.2 \%)$ & \\
\hline \multicolumn{6}{|l|}{ Obesity } \\
\hline Normal $(\mathrm{BMI}<25)$ & & $1344(63.3 \%)$ & $156(62.7 \%)$ & $1188(63.4 \%)$ & \multirow{2}{*}{0.827} \\
\hline Overweight $(\mathrm{BMI} \geq 25)$ & & $780(36.7 \%)$ & $93(37.3 \%)$ & $687(36.6 \%)$ & \\
\hline \multicolumn{6}{|l|}{ Past medical history } \\
\hline \multirow{2}{*}{ Hypertension } & No & $1234(51.7 \%)$ & $290(56.6 \%)$ & $944(50.4 \%)$ & \multirow{2}{*}{0.012} \\
\hline & Yes & $1153(48.3 \%)$ & $222(43.4 \%)$ & $931(49.6 \%)$ & \\
\hline \multirow{2}{*}{$\begin{array}{l}\text { Cerebrovascular } \\
\text { disease }\end{array}$} & No & $2272(95.4 \%)$ & $486(95.5 \%)$ & $1786(95.4 \%)$ & \multirow{2}{*}{0.904} \\
\hline & Yes & $110(4.6 \%)$ & $23(4.5 \%)$ & $87(4.6 \%)$ & \\
\hline \multirow{2}{*}{ Cardiac disease } & No & $2181(91.5 \%)$ & $470(92.2 \%)$ & $1711(91.3 \%)$ & \multirow{2}{*}{0.518} \\
\hline & Yes & $204(8.5 \%)$ & $40(7.8 \%)$ & $164(8.7 \%)$ & \\
\hline \multirow{2}{*}{ Hyperlipidemia } & No & $1652(69.4 \%)$ & $357(70.4 \%)$ & $1295(69.1 \%)$ & \multirow{2}{*}{0.559} \\
\hline & Yes & $730(30.6 \%)$ & $150(29.6 \%)$ & $580(30.9 \%)$ & \\
\hline \multirow{2}{*}{ Diabetic disease } & No & $2186(91.9 \%)$ & $467(92.5 \%)$ & $1719(91.7 \%)$ & \multirow{2}{*}{0.562} \\
\hline & Yes & $194(8.1 \%)$ & $38(7.5 \%)$ & $156(8.3 \%)$ & \\
\hline BMI, body mass index & & & & & \\
\hline
\end{tabular}


Table 2. The prevalence of CTS and CuTS.

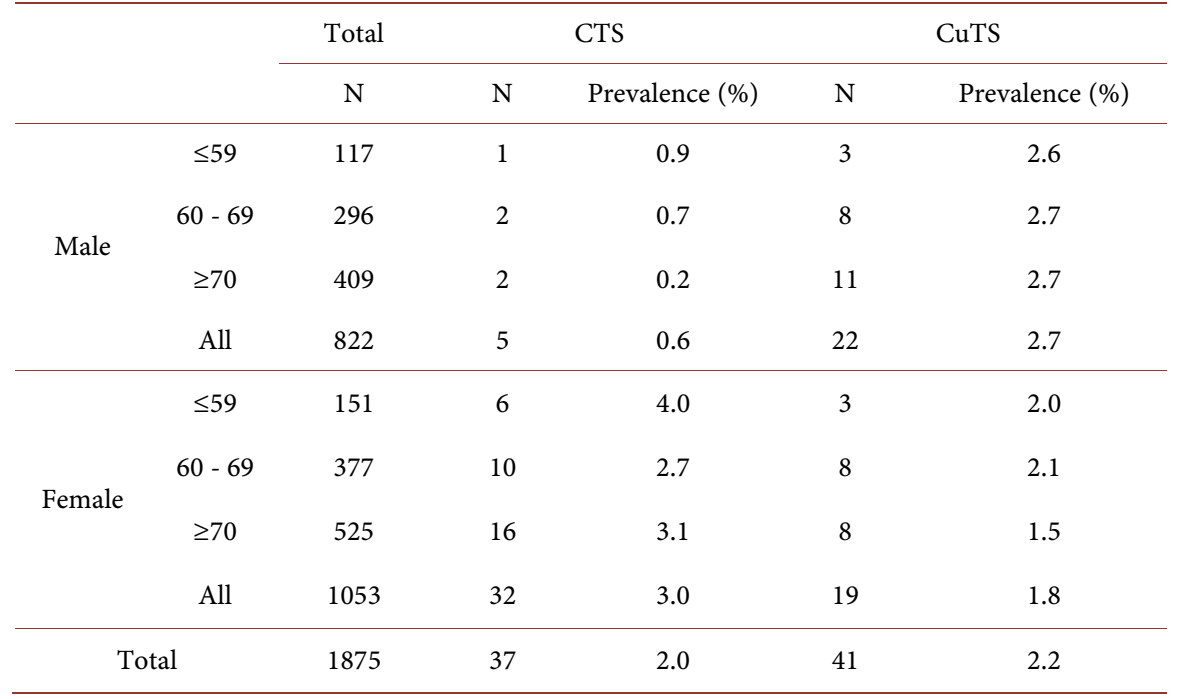

\subsection{Comparison of Characteristics between Subjects with and without CTS}

Among the female subjects, the prevalence of CTS was significantly higher in those with borderline/definite hypertension compared to that in those with normal blood pressure; however, such a trend was not observed in the male subjects. Although there was no significant difference, the prevalence of CTS was increased as the increase of the value of $\mathrm{HbAlc}$ in female subjects. With regard to the subjective outcome, the Quick DASH score was significantly higher in the subjects with CTS compared to the subjects without CTS; however, there was no significant difference in the PCS and MCS scores of SF-12. Occupational status, smoking and alcohol preference, and medical characteristics such as obesity, Mets, and hyperlipidemia were not associated with CTS (Table 3).

\subsection{Comparison of Characteristics between Subjects with and without CuTS}

Occupational status, smoking and alcohol preference, and any medical characteristics such as obesity, Mets, hypertension, hyperlipidemia, and chronic hyperglycemia were not associated with CuTS in either the male or female subjects. The Quick DASH score was significantly higher in the subjects with CuTS compared to the subjects without CuTS in both the male and female subjects. There was no significant difference in the PCS score in both the male and female subjects; however, in female subjects, the MCS score was significantly lower in the subjects with CuTS (Table 4).

\subsection{Exploration of Associated Factors for CTS}

Female gender and hypertension were independently associated with CTS. Although no significant difference was observed, the odds ratio was higher in the subjects who smoked and had chronic hyperglycemia (Table 5). 
Table 3. Clinicodemographic factors in subjects with and without CTS.

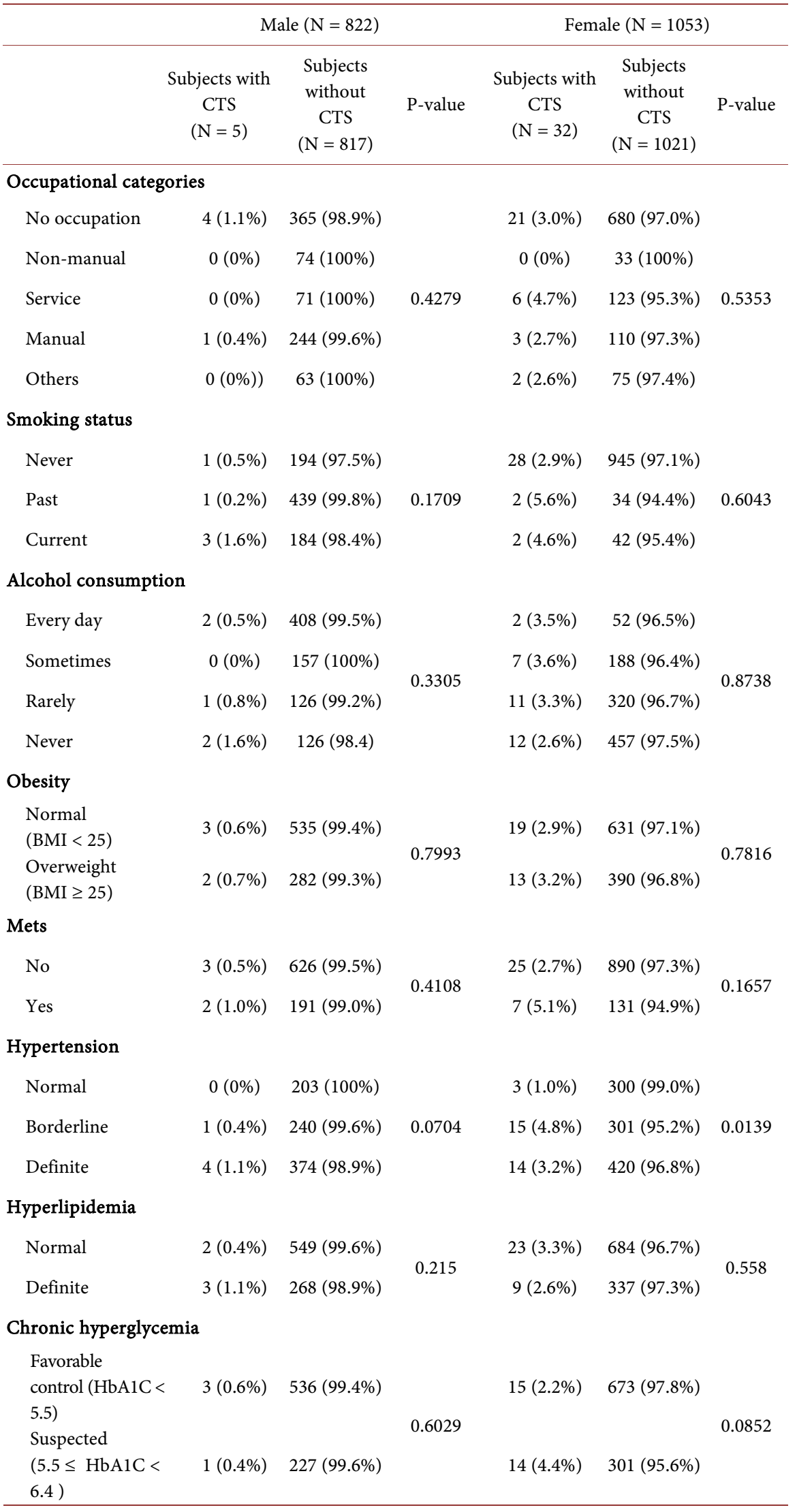




\section{Continued}

$\begin{array}{llll}\text { Definite } & & \\ (\mathrm{HbA} 1 \mathrm{C} \geq 6.5) & 1(1.8 \%) & 54(98.2 \%) & 3(6.0 \%)\end{array}$

Subjective outcome

$\begin{array}{lrrrrrr}\text { Quick DASH score } & 16.0 \pm 12.3 & 6.9 \pm 10.4 & 0.0533 & 21.0 \pm 15.8 & 10.3 \pm 12.1 & <0.001 \\ \text { SF-12 PCS score } & 32.9 \pm 10.6 & 34.3 \pm 11.6 & 0.8009 & 26.2 \pm 12.4 & 30.7 \pm 12.6 & 0.0589 \\ \text { SF-12 MCS score } & 45.7 \pm 10.5 & 45.9 \pm 9.3 & 0.9573 & 44.1 \pm 8.4 & 45.5 \pm 9.0 & 0.4095\end{array}$

BMI, body mass index; Mets, metabolic syndrome; SBP, systolic blood pressure; DBP, diastolic blood pressure; HDL-C, high density lipoprotein cholesterol; LDL-C, low density lipoprotein cholesterol; TG, triglyceride; HbAlc, hemoglobin Alc; DASH, disabilities of arm, shoulder and hand; SF-12, short form 12; PCS, physical component summary; MCS, mental component summary; SD, standard deviation.

\subsection{Exploration of Associated Factors for CuTS}

Age, gender, occupational status, smoking and alcohol preference, and any medical characteristics such as obesity, Mets, hypertension, hyperlipidemia, and chronic hyperglycemia were not associated with CuTS (Table 6).

\section{Discussion}

\subsection{Etiology of CTS}

The results of previous studies suggest that CTS occurs more commonly in women, and the incidence among women has been reported to peak at around 45 - 54 years of age. These age and gender differences may be explained at least partly by hormonal factors [3]. It has also been reported that pregnant and breast-feeding women have an increased risk of carpal tunnel syndrome [11], as well as those in their first menopausal year, taking the oral contraceptive pill, or taking hormone replacement therapy [29]. As noted in previous studies, our results showed that the prevalence of CTS was significantly higher in the female subjects when compared with the male subjects in all age groups, and female subjects aged 60 years and younger have a higher prevalence compared with older subjects.

It has been reported that several metabolic factors are associated with CTS. Nordstorm et al. reported that body mass index and obesity are strongly associated with CTS, with every 1 unit increase in body mass increasing risk of the condition by $8 \%$ [11]. The present study showed that subjects with hypertension was significantly high odds ratio of CTS regardless of age, gender, and other metabolic and factors by multivariable analysis. It has been reported that alterations in endoneural blood vessels caused by hypertension inducedmorphological and morphometric changes in the peripheralnerves [30]. Alaboratory study showed that sustained high blood pressure in adult spontaneously hypertensive rats (SHR) affected the sural nerve myelinated fibers, both morphologically and morphometrically [31]. The present study may be the first to report which directly demonstrates the association between CTS and hypertension. 
Table 4. Clinicodemographic variables according to presence of CuTS.

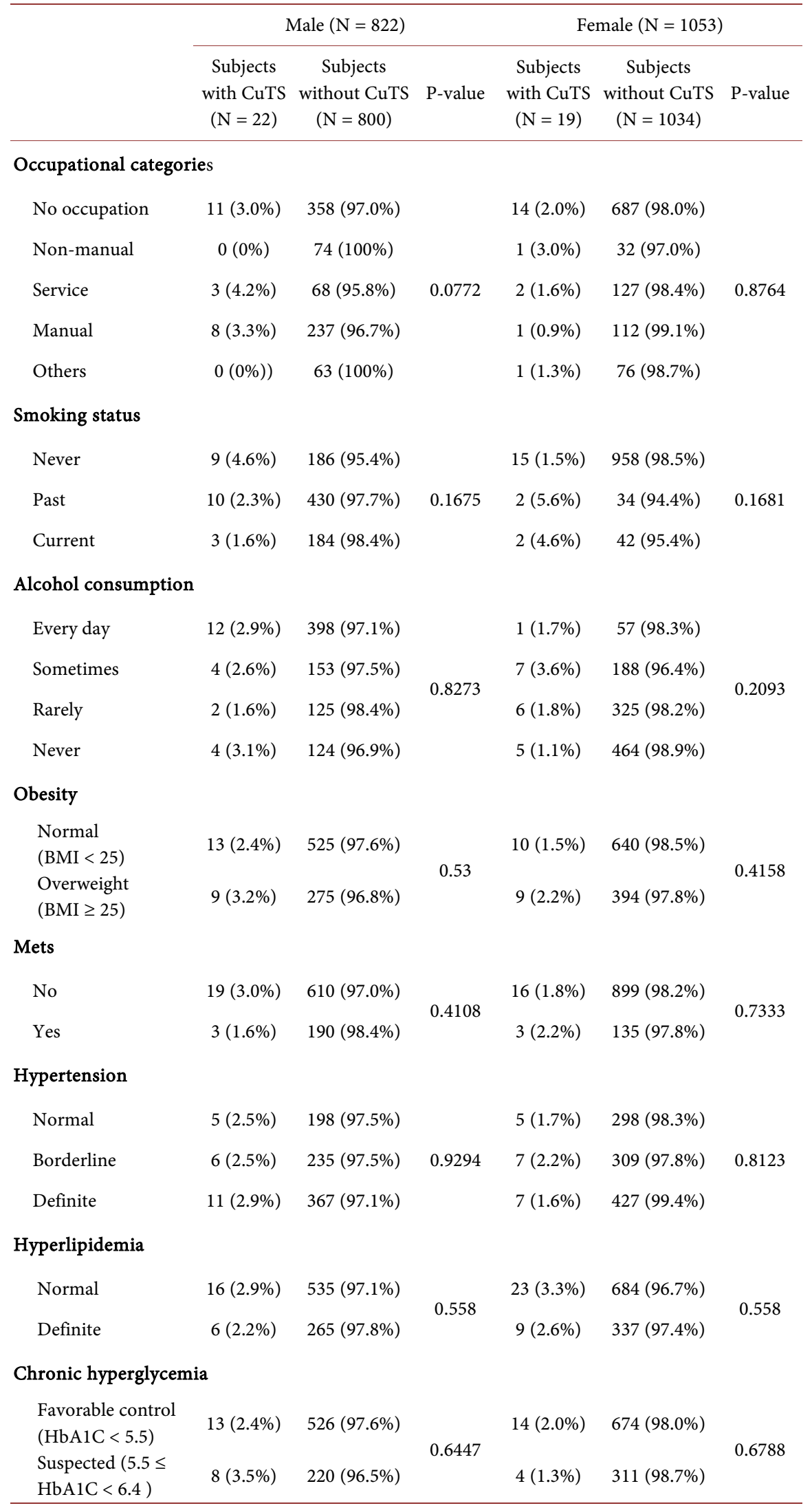




\section{Continued}

\begin{tabular}{|c|c|c|}
\hline Definite & $1(1.8 \%)$ & $54(98.2 \%)$ \\
\hline
\end{tabular}

\section{Subjective outcome}

$\begin{array}{lcccccc}\text { Quick DASH score } & 12.2 \pm 12.4 & 6.8 \pm 10.4 & 0.0184 & 19.2 \pm 12.1 & 10.4 \pm 12.3 & 0.0021 \\ \text { SF-12 PCS score } & 33.8 \pm 11.4 & 34.3 \pm 11.6 & 0.8634 & 25.4 \pm 12.4 & 30.6 \pm 12.6 & 0.085 \\ \text { SF-12 MCS score } & 43.7 \pm 9.1 & 45.9 \pm 9.3 & 0.2681 & 40.9 \pm 7.0 & 45.6 \pm 9.0 & 0.0287\end{array}$

BMI, body mass index; Mets, metabolic syndrome; SBP, systolic blood pressure; DBP, diastolic blood pressure; HDL-C, high density lipoprotein cholesterol; LDL-C, low density lipoprotein cholesterol; TG, triglyceride; HbAlc, hemoglobin Alc; DASH, disabilities of arm, shoulder and hand; SF-12, short form 12; PCS, physical component summary; MCS, mental component summary; SD, standard deviation.

Table 5. Multivariable odds ratios mutually adjusted for determinants of CTS.

\begin{tabular}{|c|c|c|c|}
\hline & Odds ratio & $95 \%$ confidence interval & $\mathrm{P}$-value \\
\hline \multicolumn{4}{|l|}{ Age } \\
\hline $40-59$ & 1 & & \\
\hline $60-69$ & 0.52 & $0.20-1.47$ & 0.2096 \\
\hline$\geq 70$ & 0.51 & $0.20-1.45$ & 0.1956 \\
\hline \multicolumn{4}{|l|}{ Gender } \\
\hline Male & 1 & & \\
\hline Female & 7.33 & $2.13-27.52$ & 0.0011 \\
\hline \multicolumn{4}{|l|}{ Occupation } \\
\hline No & 1 & & \\
\hline Yes & 0.81 & $0.37-1.69$ & 0.5865 \\
\hline \multicolumn{4}{|l|}{ Smoking status } \\
\hline Never & 1 & & \\
\hline Past & 1.08 & $0.21-4.10$ & 0.9222 \\
\hline Current & 2.77 & $0.77-8.40$ & 0.1116 \\
\hline \multicolumn{4}{|l|}{ Alcohol consumption } \\
\hline Never & 1 & & \\
\hline Current & 1.04 & $0.49-2.40$ & 0.9167 \\
\hline \multicolumn{4}{|l|}{ Obesity } \\
\hline Normal (BMI < 25) & 1 & & \\
\hline Overweight (BMI $\geq 25$ ) & 0.89 & $0.40-1.88$ & 0.7590 \\
\hline \multicolumn{4}{|l|}{ Mets } \\
\hline No & 1 & & \\
\hline Yes & 1.58 & $0.61-3.88$ & 0.3378 \\
\hline \multicolumn{4}{|l|}{ Hypertension } \\
\hline Normal & 1 & & \\
\hline Borderline & 5.56 & $1.80-24.38$ & 0.0019 \\
\hline Definite & 4.55 & $1.47-19.97$ & 0.0068 \\
\hline \multicolumn{4}{|l|}{ Hyperlipidemia } \\
\hline Normal & 1 & & \\
\hline Definite & 0.77 & $0.36-1.59$ & 0.4917 \\
\hline \multicolumn{4}{|l|}{ Chronic hyperglycemia } \\
\hline Favorable control $(\mathrm{HbA1C}<5.5)$ & 1 & & \\
\hline Suspected $(5.5 \leq \mathrm{HbA1C}<6.4)$ & 1.89 & $0.91-3.87$ & 0.0860 \\
\hline Definite (HbA1C $\geq 6.5$ ) & 2.48 & $0.67-7.34$ & 0.1586 \\
\hline
\end{tabular}


Table 6. Multivariable odds ratios mutually adjusted for determinants of CuTS.

\begin{tabular}{|c|c|c|c|}
\hline & Odds ratio & $95 \%$ confidence interval & $\mathrm{P}$-value \\
\hline \multicolumn{4}{|l|}{ Age } \\
\hline $40-59$ & 1 & & \\
\hline $60-69$ & 0.91 & $0.35-2.65$ & 0.8494 \\
\hline$\geq 70$ & 0.76 & $0.28-2.27$ & 0.5582 \\
\hline \multicolumn{4}{|l|}{ Gender } \\
\hline Male & 1 & & \\
\hline Female & 0.61 & $0.25-1.53$ & 0.1150 \\
\hline \multicolumn{4}{|l|}{ Occupation } \\
\hline No & 1 & & \\
\hline Yes & 0.7 & $0.35-1.37$ & 0.3232 \\
\hline \multicolumn{4}{|l|}{ Smoking status } \\
\hline Never & 1 & & \\
\hline Past & 0.79 & $0.31-2.00$ & 0.7258 \\
\hline Current & 0.68 & $0.20-2.02$ & 0.6308 \\
\hline \multicolumn{4}{|l|}{ Alcohol consumption } \\
\hline Never & 1 & & \\
\hline Current & 0.57 & $0.27-1.15$ & 0.5829 \\
\hline \multicolumn{4}{|l|}{ Obesity } \\
\hline Normal (BMI < 25) & 1 & & \\
\hline Overweight (BMI $\geq 25$ ) & 1.62 & $0.82-3.16$ & 0.1688 \\
\hline \multicolumn{4}{|l|}{ Mets } \\
\hline No & 1 & & \\
\hline Yes & 0.56 & $0.19-1.43$ & 0.2388 \\
\hline \multicolumn{4}{|l|}{ Hypertension } \\
\hline Normal & 1 & & \\
\hline Borderline & 1.26 & $0.54-3.03$ & 0.5581 \\
\hline Definite & 1.1 & $0.50-2.55$ & 0.7456 \\
\hline \multicolumn{4}{|l|}{ Hyperlipidemia } \\
\hline Normal & 1 & & \\
\hline Definite & 1.04 & $0.50-2.04$ & 0.9754 \\
\hline \multicolumn{4}{|l|}{ Chronic hyperglycemia } \\
\hline Favorable control $(\mathrm{HbA} 1 \mathrm{C}<5.5)$ & 1 & & \\
\hline Suspected $(5.5 \leq \mathrm{HbA} 1 \mathrm{C}<6.4)$ & 1.1 & $0.52-2.15$ & 0.9013 \\
\hline Definite (HbA1C $\geq 6.5$ ) & 0.97 & $0.15-3.45$ & 0.9128 \\
\hline
\end{tabular}

It has been reported that diabetic neuropathy is one of the most common forms of neuropathy [7]. According to several clinical studies, the prevalence of CTS is several-fold higher in DM patients than in the general population [8] [9], and the hazard ratio for CTS is 1.31 (95\%CI: 1.28 - 1.34) in DM patients [10]. Although there was no significant difference in the present study, our results 
showed that patients with chronic hyperglycemia are at a higher risk of CTS (suspected: 1.89 , definite: 2.48 ).

\subsection{Etiology of CuTS}

CuTS has been reported to be the second most common nerve entrapment in the upper limb after CTS, and several risk factors have been identified.

The prevalence of CuTS among workers varies from $2.8 \%$ to $6.8 \%$ [5] [16]. In a review by Piligian et al. [32], some work-related risk factors, such as holding a tool in the same position [16] [33], repetitive and sudden elbow flexion, and repeated trauma or pressure to the elbow at the ulnar groove, were mentioned and appeared to be common to CuTS [2]. However, the current study's results showed that occupation was not associated with CuTS. One of the possible reasons for this is that the categories used in our study might not reflect the actual physical demands of manual tasks that involve the upper extremities. In addition, the majority of the residents, including unemployed subjects, would be engaged in agriculture as a family business in addition to their own occupation. To make a precise assessment of the association between occupation and CuTS, detailed evaluations of the actual physical demants of manual tasks at each occupation are needed.

According to previous studies, smoking preference was reported to predispose the development of ulnar nerve compression at the elbow. Richardson et al. described in their small case-control study that smoking preference was associated with CuTS [15]. Furthermore, Bartels et al. also reported that only smoking was a risk factor of CuTS [12]. In contrast to previous studies, our results revealed no significant association between CuTS and smoking preference.

Few studies have investigated metabolic factors as a risk factor of CuTS. Bartels et al. reported in their hospital-based case-control study that there was no significant correlation between CuTS and diabetes mellitus, hypothyroidism, or hypertension [12]. Consistent with this report, our large epidemiologic study showed that metabolic factors, such as metabolic syndrome, obesity, hypertension, hyperlipidemia, and chronic hyperglycemia, were not associated with CuTS. Taken together, smoking preference and metabolic factors might not be associated with the onset of CuTS.

\subsection{Limitations}

The current study has several limitations. First, the area surveyed is located in a very rural area of Japan with a particularly aged population. In addition, our study population was not sufficiently large to accurately estimate the prevalence and risk factors of CTS and CUTS in the Japanese general population. A similar epidemiologic study should be performed in urban areas to eliminate regional differences and enhance the reliability of the statistical analyses. Second, there was no information on trauma, such as fracture and dislocation, in the current study. To assess the involvement in trauma to these entrapment neuropathies would be an issue in the future. Third, there might be some selection bias in this 
study. Since subjects voluntarily attended the health checkup, relatively healthy and health-conscious individuals may have participated in this study, and some individuals who make regular hospital visits may not come for an annual health checkup. Fourth, the diagnostic criteria were insufficient because nerve conduction velocity was not assessed in the diagnosis of CTS and CuTS. Last, since our research was a cross-sectional study, it was not possible to assess a causal relationship. A prospective cohort study should be done to clarify this problem.

\section{Conclusion}

In conclusion, the prevalence of CTS in the Japanese general population was $0.6 \%$ in males and $3.0 \%$ in females, and the prevalence of CuTS was $2.7 \%$ in males and $1.8 \%$ in females. Female gender and hypertension might be risk factors of CTS; however, age, gender, smoking and alcohol preference, and any medical characteristics were not associated with the onset of CuTS.

\section{References}

[1] Von Shroeder, H.P. and Botte, M.J. (1996) Carpal Tunnel Syndrome. Hand Clinics, 12, 643-655.

[2] McPherson, S.A. and Meals, R.A. (1992) Cubital Tunnel Syndrome. Orthopedic Clinics of North America, 23, 111-123.

[3] Stevens, J.C., Sun, S., Beard, C.M., et al. (1988) Carpal Tunnel Syndrome in Rochester, Minnesota, 1961 to 1980. Neurology, 38, 134-138.

https://doi.org/10.1212/WNL.38.1.134

[4] Mediouni, Z., Bodin, J., Dale, A.M., Herquelot, E., Carton, M., Leclerc, A., Fouquet, N., Dumontier, C., Roquelaure, Y., Evanoff, B.A. and Descatha, A. (2015) Carpal Tunnel Syndrome and Computer Exposure at Work in Two Large Complementary Cohorts. BMJ Open, 5, e008156. https://doi.org/10.1136/bmjopen-2015-008156

[5] Mondelli, M., Giannini, F., Ballerini, M., Ginanneschi, F. and Martorelli, E. (2005) Incidence of Ulnar Neuropathy at the Elbow in the Province of Siena (Italy). Journal of the Neurological Sciences, 234, 5-10. https://doi.org/10.1016/j.jns.2005.02.010

[6] Ferry, S., Pritchard, T., Keenan, J., et al. (1998) Estimating the Prevalence of Delayed Median Nerve Conduction in the General Population. British Journal of Rheumatology, 37, 630-635. https://doi.org/10.1093/rheumatology/37.6.630

[7] Tesfaye, S., Boulton, A.J., Dyck, P.J., Freeman, R., Horowitz, M., Kempler, P., Lauria, G., Malik, R.A., Spallone, V., Vinik, A., Bernardi, L. and Valensi, P. (2010) Diabetic Neuropathies: Update on Definitions, Diagnostic Criteria, Estimation of Severity, and Treatments. Diabetes Care, 33, 2285-2293. https://doi.org/10.2337/dc10-1303

[8] Makepeace, A., Davis, W.A., Bruce, D.G. and Davis, T.M. (2008) Incidence and Determinants of Carpal Tunnel Decompression Surgery in Type 2 Diabetes: The Fremantle Diabetes Study. Diabetes Care, 31, 498-500. https://doi.org/10.2337/dc07-2058

[9] Perkins, B.A., Olaleye, D. and Bril, V. (2002) Carpal Tunnel Syndrome in Patients with Diabetic Polyneuropathy. Diabetes Care, 25, 565-569. https://doi.org/10.2337/diacare.25.3.565

[10] Chen, L.H., Li, C.Y., Kuo, L.C., Wang, L.Y., Kuo, K.N., Jou, I.M. and Hou, W.H. (2015) Risk of Hand Syndromes in Patients with Diabetes Mellitus: A Popula- 
tion-Based Cohort Study in Taiwan. Medicine (Baltimore), 94, e1575. https://doi.org/10.1097/MD.0000000000001575

[11] Nordstrom, D.L., Vierkant, R.A., DeStefano, F. and Layde, P.M. (1997) Risk Factors for Carpal Tunnel Syndrome in a General Population. Occupational and Environmental Medicine, 54, 734-740. https://doi.org/10.1136/oem.54.10.734

[12] Bartels, R.H.M.A. and Verbeek, A.L.M. (2007) Risk Factors for Ulnar Nerve Compression at the Elbow: A Case Control Study. Acta Neurochirurgica, 149, 669-674. https://doi.org/10.1007/s00701-007-1166-5

[13] Hunt, J.R. (1916) Tardy or Late Paralysis of the Ulnar Nerve. A Form of Chronic Progressive Neuritis Developing Many Years after Fracture Dislocation of the Elbow Joint. JAMA, 66, 11-15. https://doi.org/10.1001/jama.1916.02580270015003

[14] Jeon, I.H., Oh, C.W., Kyung, H.S., Park, I.H. and Kim, P.T. (2006) Tardy Ulnar Nerve Palsy in Cubitus Varus Deformity Associated with Ulnar Nerve Dislocation in Adults. Journal of Shoulder and Elbow Surgery, 15, 474-478. https://doi.org/10.1016/j.jse.2005.10.009

[15] Richardson, J.K. and Jamieson, S.H. (2004) Cigarette Smoking and Ulnar Mononeuropathy at the Elbow. American Journal of Physical Medicine \& Rehabilitation, 83, 730-734. https://doi.org/10.1097/01.PHM.0000137316.54347.B8

[16] Descatha, A., Leclerc, A., Chastang, J.-F., Roquelaure, Y. and the Study Group on Repetitive Work (2004) Incidence of Ulnar Nerve Entrapment at the Elbow in Repetitive Work. Scandinavian Journal of Work, Environment \& Health, 30, 234-240. https://doi.org/10.5271/sjweh.784

[17] Otani, K., Takegami, M., Fukumori, N., Sekiguchi, M., Onishi, Y., Yamazaki, S., et al. (2012) Locomotor Dysfunction and Risk of Cardiovascular Disease, Quality of Life, and Medical Costs: Design of the Locomotive Syndrome and Health Outcome in Aizu Cohort Study (LOHAS) and Baseline Characteristics of the Study Population. Journal of Orthopaedic Science, 17, 261-271. https://doi.org/10.1007/s00776-012-0200-5

[18] Otoshi, K., Takegami, M., Sekiguchi, M., Onishi, Y., Yamazaki, S., Otani, K., Shishido, H., Fukuhara, S., Kikuchi, S. and Konno, S. (2015) Chronic Hyperglycemia Increases the Risk of Lateral Epicondylitis: The Locomotive Syndrome and Health Outcome in Aizu Cohort Study (LOHAS). Springerplus, 11, 407.

https://doi.org/10.1186/s40064-015-1204-3

[19] Examination Committee of Criteria for "Obesity Disease" in Japan, Japan Society for the Study of Obesity (2002) New Criteria for "Obesity Disease” in Japan. Circulation Journal, 66, 987-992. https://doi.org/10.1253/circj.66.987

[20] Ogihara, T., Kikuchi, K., Matsuoka, H., Fujita, T., Higaki, J., Horiuchi, M., et al. (2009) The Japanese Society of Hypertension Guidelines for the Management of Hypertension (JSH 2009). Hypertension Research, 32, 3-107.

https://doi.org/10.1038/hr.2009.34

[21] Committee of the Japan Diabetes Society on the Diagnostic Criteria of Diabetes Mellitus (2010) Report of the Committee on the Classification and Diagnostic Criteria of Diabetes Mellitus. Journal of Diabetes Investigation, 1, 212-228. https://doi.org/10.1111/j.2040-1124.2010.00074.x

[22] Hata, Y., Mabuchi, H., Saito, Y., Itakura, H., Egusa, G., Ito, H., Working Committee on JAS Guideline for Diagnosis and Treatment of Hyperlipidemias, et al. (2002) Report of the Japan Atherosclerosis Society (JAS) Guideline for Diagnosis and Treatment of Hyperlipidemia in Japanese Adults. Journal of Atherosclerosis and Thrombosis, 9, 1-27. https://doi.org/10.5551/jat.9.1 
[23] Examination Committee of Criteria for Metabolic Syndrome (2005) The Definition and Criteria of Metabolic Syndrome. The Journal of the Japanese Society of Internal Medicine, 94, 794-809. (In Japanese) https://doi.org/10.2169/naika.94.794

[24] Imaeda, T., Toh, S., Wada, T., Uchiyama, S., Okinaga, S., Kusunose, K., et al. (2006) Validation of the Japanese Society for Surgery of the Hand Version of the Quick Disability of the Arm, Shoulder, and Hand (QuickDASH-JSSH) Questionnaire. Journal of Orthopaedic Science, 11, 248-253. https://doi.org/10.1007/s00776-006-1013-1

[25] Fukuhara, S. and Suzukamo, Y. (2004) Manual of SF-36v2 Japanese Version. Institute for Health Outcomes and Process Evaluation Research, Kyoto.

[26] Amirfeyz, R., Clark, D., Parsons, B., Melotti, R., Bhatia, R., Leslie, I., et al. (2011) Clinical Tests for Carpal Tunnel Syndrome in Contemporary Practice. Archives of Orthopaedic and Trauma Surgery, 131, 471-474. https://doi.org/10.1007/s00402-010-1150-z

[27] Fowler, J.R., Cipolli, W. and Hanson, T. (2015) A Comparison of Three Diagnostic Tests for Carpal Tunnel Syndrome Using Latent Class Analysis. The Journal of Bone and Joint Surgery. American Volume, 97, 1958-1961. https://doi.org/10.2106/JBJS.O.00476

[28] Buehler, M.J. and Thayer, D.T. (1988) The Elbow Flexion Test. A Clinical Test for the Cubital Tunnel Syndrome. Clinical Orthopaedics and Related Research, 233, 213-216.

[29] Solomon, D.H., Katz, J.N., Bohn, R., et al. (1999) Non-Occupational Risk Factors for Carpal Tunnel Syndrome. Journal of General Internal Medicine, 14, 310-314. https://doi.org/10.1046/j.1525-1497.1999.00340.x

[30] Sabbatini, M., Vega, J.A. and Amenta, F. (1996) Peripheral Nerve Vascular Changes in Spontaneously Hypertensive Rats. Neuroscience Letters, 217, 85-88. https://doi.org/10.1016/0304-3940(96)13054-8

[31] Sanada, L.S., Kalil, A.L.R., Tavares, M.R., Neubern, M.C.M., Salgado, H.C. and Fazan, V.P.S. (2012) Sural Nerve Involvement in Experimental Hypertension: Morphology and Morphometry in Male and Female Normotensive Wistar-Kyoto (WKY) and Spontaneously Hypertensive Rats (SHR). BMC Neuroscience, 13, 24. https://doi.org/10.1186/1471-2202-13-24

[32] Piligian, G., Herbert, R., Hearns, M., Dropkin, J., Landsbergis, P. and Cherniack, M. (2000) Evaluation and Management of Chronic Work-Related Musculoskeletal Disorders of the Distal Upper Extremity. American Journal of Industrial Medicine, 37, 75-93. https://doi.org/10.1002/(SICI)1097-0274(200001)37:1<75::AID-AJIM7>3.0.CO;2-4

[33] Van Rijn, R.M., Huisstede, B.M., Koes, B.W. and Burdorf, A. (2009) Associations between Work-Related Factors and Specific Disorders at the Elbow: A Systematic Literature Review. Rheumatology (Oxford), 48, 528-536.

https://doi.org/10.1093/rheumatology/kep013 